\title{
Implementation and outcomes of an urban mobile adult extracorporeal life support program
}

Joseph Hadaya, MD, ${ }^{\mathrm{a}}$ Yas Sanaiha, MD, ${ }^{\mathrm{a}}$ Vadim Gudzenko, MD, ${ }^{\mathrm{b}}$ Nida Qadir, MD, ${ }^{\mathrm{c}}$ Sumit Singh, MD, ${ }^{\mathrm{b}}$ Ali Nsair, MD, ${ }^{\mathrm{d}}$ Nam Yong Cho, BS, ${ }^{\mathrm{a}}$ Richard J. Shemin, MD, ${ }^{\mathrm{a}}$ and Peyman Benharash, MD, ${ }^{\mathrm{a}}$ the UCLA Extracorporeal Life Support Group*

\section{ABSTRACT}

Objective: Although extracorporeal life support (ECLS) has been increasingly adopted as rescue therapy for cardiac and pulmonary failure, it remains limited to specialized centers. The present study reports our institutional experience with mobile ECLS across broad indications, including postcardiotomy syndrome, cardiogenic shock, and COVID-19 acute respiratory failure.

Methods: We performed a retrospective review of all patients transported to our institution through our mobile ECLS program from January 1, 2018, to January 15, 2021.

Results: Of 110 patients transported to our institution on ECLS, $65.5 \%$ required venovenous, $30.9 \%$ peripheral venoarterial, and $3.6 \%$ central venoarterial support. The most common indications for mobile ECLS were acute respiratory failure $(46.4 \%)$, COVID-19-associated respiratory failure (19.1\%), cardiogenic shock $(18.2 \%)$ and postcardiotomy syndrome $(11.8 \%)$. The median pre-ECLS $\mathrm{PaO}_{2}: \mathrm{FlO}_{2}$ for venovenous-ECLS was $64 \mathrm{~mm} \mathrm{Hg}$ (interquartile range [IQR], 53-75 mm Hg) and $95.8 \mathrm{~mm} \mathrm{Hg}(\mathrm{IQR}, 55-227 \mathrm{~mm} \mathrm{Hg})$ for venoarterial-ECLS, whereas median $\mathrm{pH}$ and base deficit were 7.25 (IQR, 7.16-7.33) and $7 \mathrm{mmol} / \mathrm{L}(\mathrm{IQR}, 4-11 \mathrm{mmo} / \mathrm{L})$ for those requiring venoarterial-ECLS. Patients were transported using a ground ambulance from 50 institutions with a median distance of 27.5 miles (IQR, 18.7-48.0 miles). Extracorporeal circulation was established within a median of 45 minutes (IQR, 30-55 minutes) after team arrival. Survival to discharge was $67.3 \%$ for those requiring venovenous-ECLS for non-COVID-19 respiratory failure, $52.4 \%$ for those with COVID-19\%, and $54.1 \%$ for those requiring venoarterial-ECLS.

Conclusions: Patients can be safely and expeditiously placed on ECLS across broad indications, utilizing ground transportation in an urban setting. Clinical outcomes are promising and comparable to institutional non-transfers and those reported by Extracorporeal Life Support Organization. (JTCVS Techniques 2022;12:78-92)

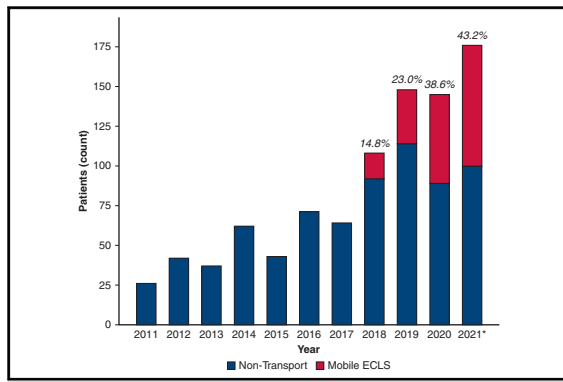

Growth of an institutional extracorporeal life support program over 1 decade.

\section{CENTRAL MESSAGE}

ECLS initiation and transport using a lean team in an urban setting can provide acceptable outcomes across broad indications, including COVID-19 respiratory failure and postcardiotomy syndrome.

\section{PERSPECTIVE}

ECLS requires significant institutional resources. Although interhospital transfer may extend ECLS services, patients are often unstable for conventional transport. We developed a mobile ECLS program emphasizing community outreach, expedient cannulation, and ground-based transportation that shows promising outcomes across cardiac and pulmonary indications.

See Commentary on page 93.
From the ${ }^{\mathrm{a}}$ Division of Cardiac Surgery, Department of Surgery, ${ }^{\mathrm{b}}$ Division of Critical Care Medicine, Department of Anesthesiology and Perioperative Medicine, and Divisions of ${ }^{\mathrm{c}}$ Pulmonary and Critical Care Medicine and ${ }^{\mathrm{d}}$ Cardiology, Department of Medicine, University of California, Los Angeles, Los Angeles, Calif.

Accepted for the 46th Annual Meeting of the Western Thoracic Surgical Association, Vail, Colorado, June 24-27, 2020.

* A complete list of UCLA Extracorporeal Life Support Group members can be found in the Acknowledgments.

Received for publication March 27, 2021; accepted for publication Dec 4, 2021; available ahead of print Jan 23, 2022.
Address for reprints: Peyman Benharash, MD, UCLA David Geffen School of Medicine, CHS 62-249, 10833 Le Conte Ave, Los Angeles, CA 90095 (E-mail: Pbenharash@mednet.ucla.edu). 2666-2507

Copyright (C) 2022 The Author(s). Published by Elsevier Inc. on behalf of The American Association for Thoracic Surgery. This is an open access article under the CC BY-NC-ND license (http://creativecommons.org/licenses/by-nc-nd/4.0/). https://doi.org/10.1016/j.xjtc.2021.12.011 


$$
\begin{aligned}
& \text { Abbreviations and Acronyms } \\
& \text { ECLS }=\text { extracorporeal life support } \\
& \text { ELSO }=\text { Extracorporeal Life Support Organization } \\
& \text { ICU }=\text { intensive care unit } \\
& \text { VA }=\text { venoarterial } \\
& \text { VIS }=\text { Vasoactive Inotrope Score } \\
& \text { VV }=\text { venovenous }
\end{aligned}
$$

Video clip is available online.

Utilization of extracorporeal life support (ECLS) for rescue of patients with severe respiratory and cardiovascular compromise has seen a dramatic rise over the past 15 years. ${ }^{1-4}$ Following decades of relative stagnation and conflicting results, ECLS is now generally accepted as an effective bridge to recovery or organ replacement..$^{5-7}$ Advances in miniaturization of blood circuits and cannulae as well as safety mechanisms to prevent catastrophic failure have allowed for wide adoption of ECLS. Nonetheless, management of patients on ECLS remains complex and resource intensive, with few centers offering this therapy.

On a national level, approximately one-third of patients receiving ECLS in the United States originate from another hospital. ${ }^{8}$ Several dedicated programs transport candidates to experienced ECLS centers though few initiate support at referring facilities (retrieval). ${ }^{9-12}$ Although many such programs use aircrafts and specialized teams to have a wide reach, the application of this concept to urban and increasingly congested areas remains limited. Moreover, most retrieval programs have focused on respiratory indications and venovenous (VV) ECLS. Reports of retrieval for COVID-19 respiratory failure, as well as for large cohorts of venoarterial (VA) ECLS, including postcardiotomy syndrome, are lacking. Herein, we report our institutional experience with a transport and cannulation team that utilizes ground transportation in a major metropolitan city over the past 3 years across all ECLS indications.

\section{METHODS \\ Program Development}

Our institution has maintained an ECLS program since 1988 and accepted transfers from referring hospitals for patients already supported on ECLS. In 2018, we expanded our program to provide mobile ECLS services, including cannulation and transportation by a dedicated team. Given the abundance of hospitals in Southern California, we focused on developing a sustainable ground transportation-based program for cardiac and pulmonary support.

\section{Patient Selection}

All patients referred to the University of California, Los Angeles Health System for mobile ECLS from January 1, 2018, to January 15, 2021, were included in this analysis.

Patients are referred through an institute-wide transfer center and are medically screened by an attending cardiothoracic surgeon. An abbreviated financial screen is performed by an administrative team; lack of insurance does not preclude acceptance for ECLS. Following discussion with the referring physician, a multidisciplinary team, including a cardiothoracic surgeon and intensivist, evaluate candidacy for ECLS. Patients who are accepted and deemed unstable are placed and transported on ECLS by the mobile team.

Both VA- and VV-ECLS modalities are evaluated on an individualized basis. We consider patients for venovenous ECLS for refractory hypoxemic or hypercapnic respiratory failure with $\mathrm{PaO}_{2} / \mathrm{FiO}_{2}<100 \mathrm{~mm} \mathrm{Hg}$ or $\mathrm{pH}<7.2$ despite maximal ventilatory support. Suitable patients have typically failed medical therapies, including neuromuscular blockade and prone positioning. For COVID-19 respiratory failure, ideal candidates are those intubated $<7$ days, younger than age 60 years (initially age 65 years), with body mass index $<45$, in addition to the above parameters. Selection criteria for COVID-19 evolved because multicenter data suggested poor survival for those intubated for prolonged durations or of advanced age. Patients are considered for VA-ECLS for cardiogenic shock and postcardiotomy syndrome. Select cases of extracorporeal cardiopulmonary resuscitation for drug overdose and refractory arrhythmias have been considered when technically feasible. Similarly, patients who are candidates for heart or lung transplantation are accepted for mobile ECLS. Exclusion criteria include unrecoverable cardiac or pulmonary injury; active, uncontrollable hemorrhage; intracranial hemorrhage or major stroke; preexisting moribund condition; disseminated malignancy; unwitnessed cardiac arrest; aortic dissection; and no access for peripheral cannulation.

\section{Team and Cannulation Approach}

A team consisting of a surgeon, assistant, perfusionist, respiratory therapist, critical-care trained nurse, 2 emergency medical technicians, and an intensivist in select cases, are deployed to referring hospital using a ground ambulance. Before deployment, the referring physician discusses ECLS with the patient's surrogate decision maker to ensure alignment with goals of care. Emergency surgical privileges from the referring hospital are obtained for cannulation. This process varies according to each hospital's bylaws, but generally entails communication with the chief medical officer and medical staff office and verification of employment and liability insurance, and can be accomplished within an hour. Equipment requested from the referring hospital includes an ultrasound machine with vascular probe, operating room pack, and basic surgical tray. We utilize a simplified transport circuit (Figure E1) consisting of a centrifugal pump with crystalloid prime.

Our preferred approach is percutaneous femoral cannulation at the bedside unless the patient is in the operating room with an open chest. Routinely used by our team, this cannulation strategy is expeditious and obviates the need for fluoroscopy or transesophageal echocardiography, which is typically limited at referring hospitals. In cases of postcardiotomy syndrome, femoral cannulation is used unless the patient's chest cannot be closed, or anatomic factors preclude retrograde perfusion through the leg. For patients placed on VAECLS through the femoral vessels, a distal perfusion cannula $(6 \mathrm{Fr}-9 \mathrm{Fr}$ wire-reinforced introducer sheath) is placed in the ipsilateral superficial femoral artery via surgical cutdown and attached to the ECLS circuit. Additional details regarding cannulation, transportation, patient care, and logistics are provided in the Appendix E1.

\section{Data Collection, Definitions, and Statistical Analysis}

Our institutional database was retrospectively reviewed for all patients transported on ECLS from January 1, 2018, to January 15, 2021 
Demographics, clinical characteristics, organ support modalities, laboratory findings, and outcomes were tabulated. Off-hours cannulation was considered as ECLS cannulation from $6 \mathrm{pm}$ to 6 am, weekends or holidays. Total transport time was considered as time from team departure from our institution to arrival back at our intensive care unit (ICU). Cannulation time was considered as the time from arrival to referring hospital to initiation of ECLS.

Comorbidities and complications were defined in concordance with the Extracorporeal Life Support Organization (ELSO) definitions. Acute kidney injury was defined as an increase in serum creatinine to $1.5 \times$ baseline or need for renal replacement therapy. Hepatic dysfunction was defined as transaminases $>200 \mathrm{IU} / \mathrm{L}$ or international normalized ratio $>1.5$. Immunosuppression did not include patients receiving stress dose steroids. The Vasoactive Inotrope Score (VIS), a validated score for outcomes in cardiogenic shock and following cardiac surgery, was used to quantify the amount of cardiovascular support required. ${ }^{13,14}$ The VIS can be conceptually considered as dopamine or dobutamine equivalents in milligrams/kilograms/minute, and was calculated using the following equation: VIS $=$ dopamine $(\mathrm{mg} / \mathrm{kg} / \mathrm{min})+$ dobutamine $(\mathrm{mg} / \mathrm{kg} /$ $\mathrm{min})+100 \times$ epinephrine $(\mathrm{mg} / \mathrm{kg} / \mathrm{min})+10 \times$ milrinone $(\mathrm{mg} / \mathrm{kg} /$ $\min )+10,000 \times$ vasopressin $(\mathrm{U} / \mathrm{kg} / \mathrm{min})+100$ norepinephrine $(\mathrm{mg} / \mathrm{kg} /$ min). The Survival After Veno-Arterial Extracorporeal Membrane Oxygenation and Respiratory Extracorporeal Membrane Oxygenation Survival Prediction scores were calculated as previously described. ${ }^{15,16} \mathrm{Me}-$ chanical complications included oxygenator or pump failure, unplanned circuit exchange, or addition/replacement of cannula. Neurologic complications included brain death, seizures, or central nervous system ischemia, infarction, or hemorrhage demonstrated on computed tomography or magnetic resonance imaging.

Continuous variables are reported as mean $\pm \mathrm{SD}$ or median and interquartile range (IQR) if non-normally distributed, and categorical variables reported as count and percent. Categorical variables were compared using Fisher exact test and continuous variables using the Mann-Whitney $U$ test. Statistical significance was considered at $\alpha<0.05$. Survival to discharge was compared with rates reported by the ELSO and to institutional nontransports. ${ }^{1}$ The Institutional Review Board at the University of California, Los Angeles, approved the study protocol and publication of data. Patient written consent for the publication of the study data was waived by the institutional review board due to retrospective nature and inability to consent subjects (No. 12-000805, approved June 25, 2019).

\section{RESULTS}

\section{Patient Demographic and Clinical Characteristics}

During the study period, 110 patients were transported on ECLS, of whom 100 were cannulated by our team. The growth of our mobile program mirrored growth in our adult ECLS program (Figure 1). The mean age was $44.7 \pm 14.1$ years and most patients were men $(74.6 \%)$. The majority of patients $(65.5 \%)$ were placed on VVECLS, $30.9 \%$ on peripheral VA-ECLS, whereas $3.6 \%$ required central VA support (Table 1). All patients were cannulated successfully with no vascular injuries, perforation, or retroperitoneal bleeding. A second drainage cannula placed in the internal jugular vein was required in 2 patients due to poor venous drainage. The most common indication for mobile ECLS was acute respiratory failure $(46.4 \%$ non-COVID$19 \% ; 19.1 \%$ COVID-19) followed by cardiogenic shock $(18.2 \%)$ (Table 1).

Pre-ECLS clinical characteristics of patients are reported in Table 2. The most common major organ dysfunction was acute kidney injury for both VA $(75.7 \%)$ and VV (31.5\%) groups. A significant proportion of patients $(43.2 \%)$ placed on VA-ECLS had experienced prior cardiac arrest,

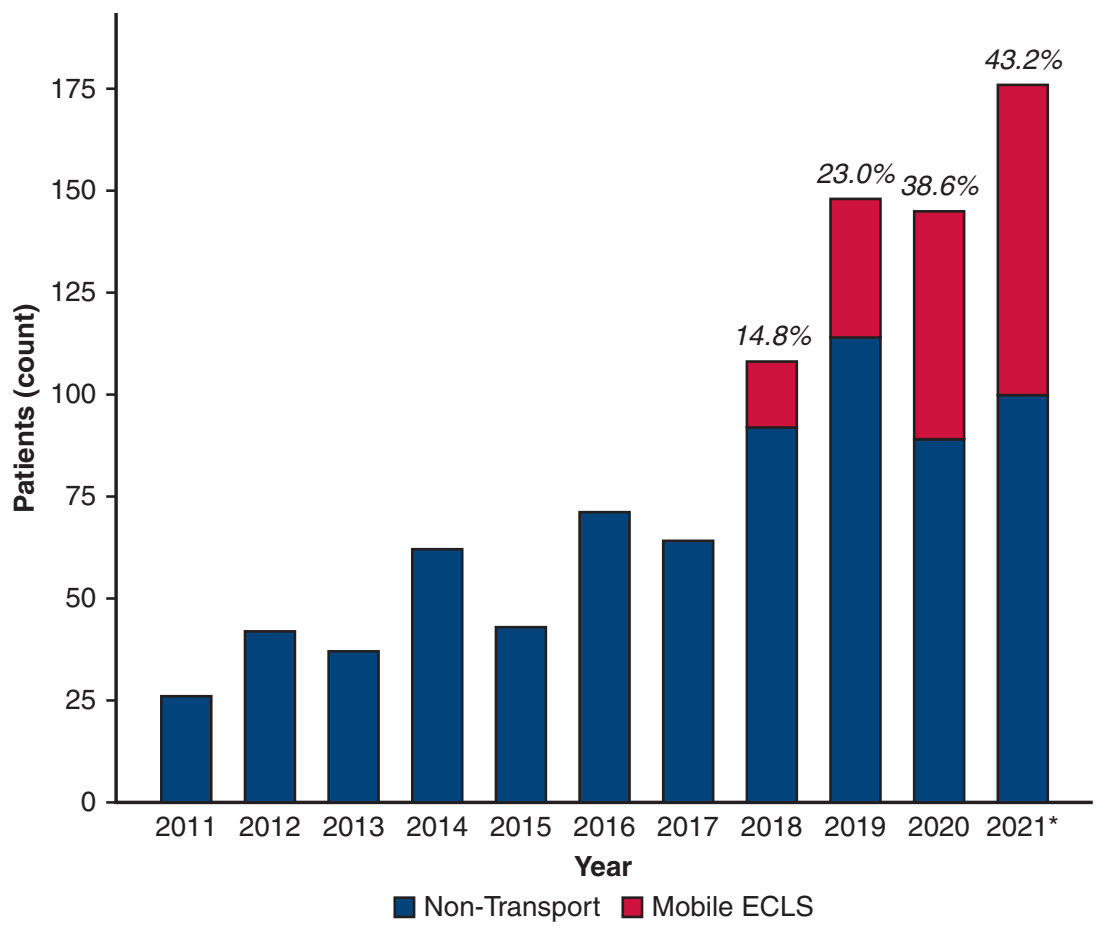

FIGURE 1. Growth of institutional adult ECLS program from 2011 to 2021. Proportion of mobile extracorporeal life support (ECLS) cases depicted as sum of annual volume. Volume for 2021 estimated based on cannulations to date (January-March 2021). 
TABLE 1. Demographic characteristics and clinical indication for extracorporeal life support (ECLS) among patients transported on ECLS

\begin{tabular}{lc}
\hline Characteristic or indication & All mobile ECLS $(\mathbf{N}=\mathbf{1 1 0})$ \\
\hline Age $(\mathrm{y})$ & $44.7(14.1)$ \\
Sex & \\
Male & $82(74.6)$ \\
Female & $28(25.4)$ \\
Race & \\
White & $46(41.8)$ \\
Hispanic & $47(42.7)$ \\
Black & $8(7.3)$ \\
Asian & $9(8.2)$ \\
BMI (kg/m $\left.{ }^{2}\right)$ & $30.8(7.6)$ \\
ECLS configuration & \\
Venovenous, peripheral & $72(66.4)$ \\
Venoarterial, central & $4(3.6)$ \\
Venoarterial, peripheral & $33(30.0)$ \\
Indication & \\
Acute respiratory failure & $51(46.4)$ \\
COVID-19 & $21(19.1)$ \\
Chronic respiratory failure & $1(0.9)$ \\
Cardiogenic shock & $20(18.2)$ \\
Postcardiotomy syndrome & $13(11.8)$ \\
ECPR & $4(3.6)$ \\
\hline
\end{tabular}

Values are presented as n (\%) or mean $\pm \mathrm{SD}$. BMI, Body mass index; $E C P R$, extracorporeal cardiopulmonary resuscitation.

including 4 who were cannulated during cardiac arrest. An intra-aortic balloon pump or percutaneous ventricular assist device were in place before cannulation in $48.9 \%$ of those requiring VA-ECLS. Prone positioning and paralytics were utilized in $45.2 \%$ and $95.9 \%$ of those placed on VV-ECLS. A significant proportion of the cohort received dialysis ( $29.7 \%$ for VA vs $12.3 \%$ for VV) or intravenous bicarbonate $(75.7 \%$ for VA vs $43.8 \%$ for VV) before ECLS. Vasopressor or inotrope use was most common in the VA cohort, with median VIS of 35 (IQR, 10-58) for the VA group and 0.3 (IQR, 0-10) for the VV group. Respiratory Extracorporeal Membrane Oxygenation Survival Prediction and Survival After Veno-Arterial Extracorporeal Membrane Oxygenation risk class distribution are reported in Table 2, with the majority of patients for both groups at class 3 or greater risk.

All patients were intubated and mechanically ventilated before initiation of ECLS. The median time from intubation to initiation of ECLS was 12 hours (IQR, 6-16 hours) for VA-ECLS and 42 hours (IQR, 17-76 hours) for VVECLS. Patients in the VV-ECLS group required substantial ventilatory support, with median rate of 25 breaths $/ \mathrm{min}$, positive end expiratory pressure of $14 \mathrm{~cm} \mathrm{H}_{2} \mathrm{O}$, and $\mathrm{FIO}_{2}$ of $100 \%$ (Table 2). Patients on VA-ECLS required less ventilatory support, with median rate of 20 breaths/min, positive end expiratory pressure of $10 \mathrm{~cm} \mathrm{H}_{2} \mathrm{O}$, and $\mathrm{FIO} 2$ of $100 \%$.
TABLE 2. Clinical characteristics of patients transported on extracorporeal life support (ECLS) stratified by support modality

\begin{tabular}{|c|c|c|}
\hline Characteristic & $\begin{array}{l}\text { Venovenous } \\
(\mathbf{n}=\mathbf{7 3})\end{array}$ & $\begin{array}{l}\text { Venoarterial } \\
(\mathbf{n}=\mathbf{3 7})\end{array}$ \\
\hline \multicolumn{3}{|l|}{ Clinical characteristics before } \\
\hline CNS dysfunction & $5(6.9)$ & $5(13.5)$ \\
\hline Prior cardiac arrest & $4(5.5)$ & $16(43.2)$ \\
\hline $\begin{array}{l}\text { Chronic obstructive } \\
\text { pulmonary disease }\end{array}$ & $6(8.2)$ & $4(10.8)$ \\
\hline Interstitial lung disease & $6(8.2)$ & $3(8.1)$ \\
\hline Liver dysfunction & $2(2.7)$ & 7 (18.9) \\
\hline Acute kidney injury & $23(31.5)$ & $28(75.7)$ \\
\hline $\begin{array}{l}\text { Chronic } \\
\text { immunosuppression }\end{array}$ & $9(12.3)$ & $2(5.4)$ \\
\hline \multicolumn{3}{|c|}{ Respiratory support before ECLS } \\
\hline $\begin{array}{l}\text { Time from intubation } \\
\text { to cannulation (h) }\end{array}$ & $42(17-76)$ & $12(6-16)$ \\
\hline $\begin{array}{l}\text { Respiratory rate (breaths/ } \\
\text { min) }\end{array}$ & $25(18-30)$ & $20(16-26)$ \\
\hline $\mathrm{PIP}\left(\mathrm{cm} \mathrm{H}_{2} \mathrm{O}\right)$ & $30(24-35)$ & $26(22-34)$ \\
\hline $\operatorname{PEEP}\left(\mathrm{cm} \mathrm{H}_{2} \mathrm{O}\right)$ & $14(10-16)$ & $10(5-10)$ \\
\hline $\mathrm{FIO}_{2}(\%)$ & $100(100-100)$ & $100(100-100)$ \\
\hline Prone positioning & $33(45.2)$ & $1(2.7)$ \\
\hline Hand-bagging & $4(6.6)$ & $6(18.2)$ \\
\hline \multicolumn{3}{|c|}{ Organ support or therapies before ECLS } \\
\hline \multicolumn{3}{|l|}{ Vasoactive Inotrope Score } \\
\hline$\leq 5$ & $46(63.0)$ & $5(13.5)$ \\
\hline $6-20$ & $16(21.9)$ & $10(27.0)$ \\
\hline $20-50$ & $11(15.1)$ & $10(27.0)$ \\
\hline$>50$ & 0 & $12(32.4)$ \\
\hline \multicolumn{3}{|l|}{ SAVE or RESP risk class* } \\
\hline 1 & $13(17.8)$ & 0 \\
\hline 2 & $19(26.0)$ & $6(16.2)$ \\
\hline 3 & $26(35.6)$ & $11(29.7)$ \\
\hline 4 & $10(13.7)$ & $9(24.3)$ \\
\hline 5 & $5(6.9)$ & $11(29.7)$ \\
\hline IABP or PVAD & 0 & $18(48.9)$ \\
\hline Dialysis & $9(12.3)$ & $11(29.7)$ \\
\hline Intravenous bicarbonate & $32(43.8)$ & $28(75.7)$ \\
\hline Paralytics & $70(95.9)$ & $31(83.8)$ \\
\hline $\begin{array}{l}\text { Epoprostenol or nitric } \\
\text { oxide }\end{array}$ & $11(15.1)$ & $2(5.4)$ \\
\hline \multicolumn{3}{|l|}{$\begin{array}{l}\text { Pre-ECLS laboratory } \\
\text { findings }\end{array}$} \\
\hline $\mathrm{PaO}_{2}: \mathrm{FIO}_{2}(\mathrm{~mm} \mathrm{Hg})$ & $64.0(53.8-75.5)$ & $95.8(55.0-227.0)$ \\
\hline $\mathrm{pH}$ & $7.26(7.18-7.36)$ & $7.25(7.16-7.33)$ \\
\hline $\mathrm{PaCO}_{2}(\mathrm{~mm} \mathrm{Hg})$ & $61.0(48.0-77.0)$ & $43.0(37.4-52.0)$ \\
\hline $\mathrm{PaO}_{2}(\mathrm{~mm} \mathrm{Hg})$ & $61.0(47.8-77.3)$ & $69.0(52.0-159.0)$ \\
\hline Bicarbonate $(\mathrm{mmol} / \mathrm{L})$ & $27.1(22.1-31.1)$ & $18.9(15.6-22.0)$ \\
\hline Base excess (mmol/L) & $0.3(-3.0$ to 4.7$)$ & $-7.4(-11.0$ to -4.1$)$ \\
\hline
\end{tabular}

Values are presented as $\mathrm{n}(\%)$ or median (interquartile range). $C N S$, Central nervous system; $P I P$, peak inspiratory pressure; $P E E P$, positive end expiratory pressure; $F I O 2$, fraction of inspired oxygen; SAVE, Survival After Veno-Arterial Extracorporeal Membrane Oxygenation; RESP, Respiratory Extracorporeal Membrane Oxygenation Survival Prediction. IABP, intra-aortic balloon pump; $P V A D$, percutaneous ventricular assist device. *SAVE risk class reported for the venoarterial ECLS group and RESP risk class reported for the venovenous ECLS group. 
Arterial blood gas results before ECLS initiation are reported in Table 2. The median $\mathrm{PaO}_{2}: \mathrm{FIO}_{2}$ ratio for VV-ECLS was $64.0 \mathrm{~mm} \mathrm{Hg}\left(\mathrm{IQR}, 53-75 \mathrm{~mm} \mathrm{Hg}\right.$ ), with median $\mathrm{PaCO}_{2}$ of $61 \mathrm{~mm} \mathrm{Hg}$ (IQR, 48-77 mm Hg) and $\mathrm{PaO}_{2}$ of $61 \mathrm{~mm} \mathrm{Hg}$ (IQR, 47-77 mm Hg). For VA-ECLS, median $\mathrm{pH}$ was 7.25 (IQR, 7.16-7.33), with $\mathrm{PaO}_{2}$ of $69 \mathrm{~mm} \mathrm{Hg}$ (IQR, 52-159 mm $\mathrm{Hg}$ ) and base deficit of $7.4 \mathrm{mmol} / \mathrm{L}$ (IQR, 4.1-11.0 mmol/L). Characteristics by indication are reported in Table E1.

\section{Transportation Distance and Times}

The median distance from the referring hospital to our institution was 27.5 miles (IQR, 19-48 miles, range, 2-122 miles). Most transports (76.7\%) occurred on weekends, holidays, or afterhours. The median time from arrival to initiation of ECLS and total transport time were $45 \mathrm{mi}-$ nutes (IQR, 30-55 minutes) and 235 minutes (IQR, 196284 minutes), respectively. With expansion of the program, median distance traveled increased while time from arrival to cannulation slightly decreased (Figure 2).

\section{Outcomes and Complications}

Outcomes and complications of the mobile ECLS cohort are reported in Table 3. Among the VA group, major complications were neurologic $(24.3 \%)$ and limb ischemia requiring fasciotomy $(13.5 \%)$ or amputation $(2.7 \%$, failed fasciotomy). Four of 5 threatened limbs were contralateral to the arterial cannula and had an intra-aortic balloon pump or percutaneous ventricular assist device before ECLS, whereas a single case was attributed to lack of a distal perfusion catheter when cannulated by the referring hospital. Most patients on VA-ECLS required dialysis $(73.0 \%)$ or significant red blood cell transfusion $(56.8 \%)$. Among those supported via VA-ECLS, $56.8 \%$ survived to decannulation and $54.1 \%$ survived to discharge, with median time on ECLS of 136 hours (IQR, 79-207 hours), ICU length of stay of 10 days (IQR, 6-19 days), and total length of stay of 12 days (IQR, 6-27 days). For VAECLS, the majority of survivors were discharged home $(44.4 \%)$, whereas a significant proportion was transferred back to the referring hospital $(22.2 \%)$ or to skilled nursing or rehabilitation facilities $(33.3 \%)$.

Among the VV-ECLS group, $11.0 \%$ had neurologic complications, while hemolysis, limb ischemia, and cannulation site bleeding were rare. Tracheostomy was performed in $63.0 \%$ of the VV-ECLS group. Among the VV-ECLS group, $74.0 \%$ survived to decannulation and $63.0 \%$ survived to discharge, with a median ECLS duration of 238 hours (IQR, 136-587 hours), ICU length of stay of 17 days (IQR, 11-32 days), and total length of stay of 19 days (IQR, 12-37 days). Among survivors, most were discharged home $(47.9 \%)$, whereas a minority were transferred back to the referring hospital $(31.3 \%)$ or to skilled nursing or rehabilitation facilities $(20.8 \%)$.

\section{Comparison of ECLS Transports for COVID-19 Versus Non-COVID-19 Respiratory Failure}

Characteristics, organ support therapies, and pre-ECLS laboratory values for patients with COVID-19 versus non-COVID-19 respiratory failure are reported in Table 4. Patients with COVID-19 less commonly had additional organ dysfunction compared to non-COVID-19 (23.8\% vs $53.9 \% ; P=.020$ ). More intensive pre-ECLS ventilatory support was required for the COVID-19 group, including greater rate (30 vs 20 breaths $/ \mathrm{min} ; P=.002$ ) and peak inspiratory pressure ( 37 vs $25 \mathrm{~cm} \mathrm{H}_{2} \mathrm{O} ; P=.002$ ) but similar $\mathrm{FIO}_{2}$ and positive end expiratory pressure. Prone positioning $(90.5 \%$ vs $26.9 \% ; P<.001)$, intravenous bicarbonate $(85.7 \%$ vs $26.9 \% ; P<.001)$, and epoprostenol or nitric
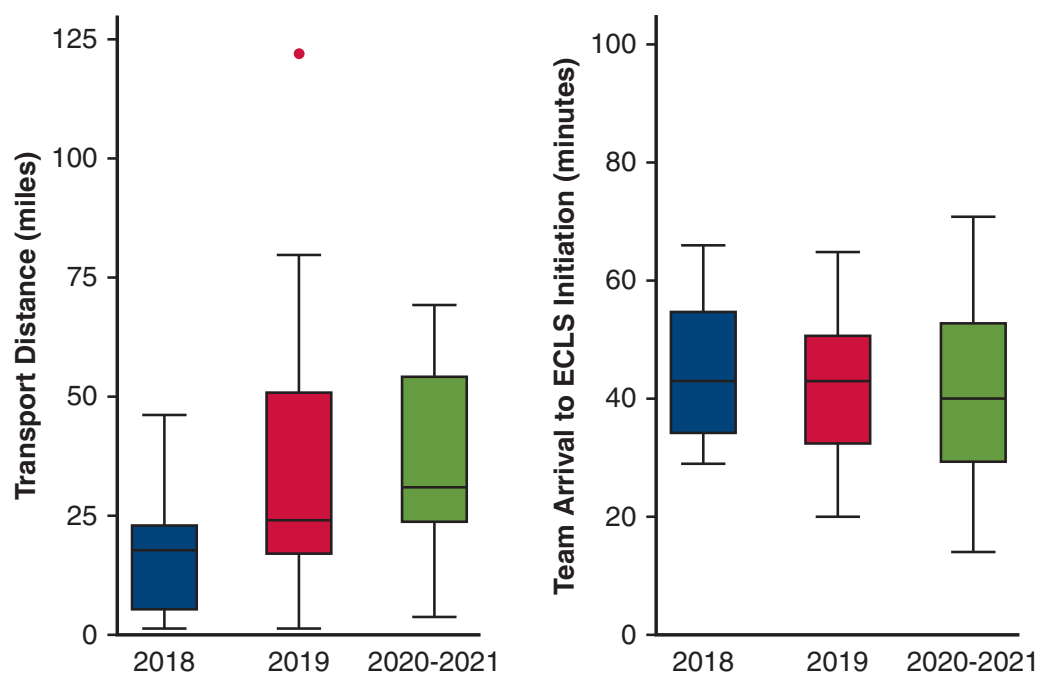

FIGURE 2. Distance traveled (A) from our institution to referring hospital and time (B) from arrival at referring hospital to initiation of extracorporeal life support (ECLS). Mobile ECLS cases from 2021 grouped with $2020(\mathrm{n}=4)$. In the box plots, box borders indicate upper and lower quartiles, horizontal line indicates median, whiskers indicate nonoutlier maximum and minimum, and extra dots indicate outliers. 
TABLE 3. Outcomes and complications of patients transported on extracorporeal life support (ECLS) stratified by support modality

\begin{tabular}{lcc}
\hline \multicolumn{1}{c}{ Outcome or complication } & $\begin{array}{c}\text { Venovenous } \\
(\mathbf{n}=\mathbf{7 3})\end{array}$ & $\begin{array}{c}\text { Venoarterial } \\
(\mathbf{n}=\mathbf{3 7})\end{array}$ \\
\hline Complications & $5(6.8)$ & $1(2.7)$ \\
Mechanical & & \\
Neurologic $\dagger$ & $8(11.0)$ & $9(24.3)$ \\
Pneumothorax & $18(24.7)$ & $2(5.4)$ \\
Pulmonary hemorrhage & $7(9.6)$ & $2(5.4)$ \\
Cannulation site bleeding & $3(4.1)$ & $3(8.1)$ \\
Severe hemolysis & $4(5.5)$ & $7(18.9)$ \\
Limb ischemia requiring fasciotomy & 0 & $5(13.5)$ \\
Limb ischemia requiring amputation & 0 & $1(2.7)$ \\
Organ support or therapies on ECLS & & \\
Dialysis & $27(37.0)$ & $27(73.0)$ \\
Tracheostomy & $46(63.0)$ & $10(27.8)$ \\
Red blood cell transfusions & & \\
0 & $13(17.8)$ & $3(8.1)$ \\
1 to 6 & $26(35.6)$ & $13(35.1)$ \\
$\quad>6$ & $34(46.6)$ & $21(56.8)$ \\
Time on ECLS (h) & $238(136-587)$ & $136(79-207)$ \\
\hline Outcomes & & \\
ICU LOS (d) & $17(11-32)$ & $10(6-19)$ \\
Total LOS (d) & $19(12-37)$ & $12(6-27)$ \\
Decannulated & $54(74.0)$ & $21(56.8)$ \\
Survived to discharge & $46(63.0)$ & $20(54.1)$ \\
\hline
\end{tabular}

Values are presented as $\mathrm{n}(\%)$ or median (interquartile range). $I C U$, Intensive care unit; $L O S$, length of stay. *Mechanical complications included unplanned circuit exchange, oxygenator or pump failure, or addition/replacement of cannulas. $\dagger$ Neurologic complications, including intracranial hemorrhage, stroke, and seizure.

oxide $(33.3 \%$ vs $7.7 \% ; P=.006)$ were more commonly used in the COVID-19 group. Median $\mathrm{PaO}_{2}: \mathrm{FIO}_{2}$ ratio was lower for COVID-19 patients than non-COVID-19 (59.0 vs $65.2 \mathrm{~mm} \mathrm{Hg} ; P=.016$ ), whereas $\mathrm{PaCO}_{2}$ and bicarbonate were similar. Longer ECLS runs and hospitalizations were evident for the COVID-19 group, with median ECLS duration of 625 hours (IQR, 403-898 hours), ICU length of stay of 32 days (IQR, 24-37 days), and total length of stay of 36 days (IQR, 25-48 days).

\section{Outcomes of ECLS Transports by Indication}

Survival to discharge for the cohort (Figure 3) was compared with patients who were placed on ECLS at our institution without prior transport. Demographic characteristics, clinical characteristics, and degree of organ dysfunction for patients cannulated at our institution without ECLS transport are reported in Table E2. When stratified by indication, there was no significant difference in survival for patients transported on ECLS (all $P$ values $>.05$ ) (Table 5). In addition, our transport cohort exhibited similar survival compared with rates reported by ELSO (Table 5).

\section{DISCUSSION}

In this analysis of our mobile ECLS program, we report clinical outcomes of 110 patients transported on ECLS via ground ambulance in an urban setting. We maintained broad indications for ECLS initiation, including postcardiotomy syndrome and COVID-19-associated respiratory failure for patients deemed unstable for conventional transport. Using a lean team, the program was able to expeditiously initiate ECLS at referring hospitals and transport all patients to our institution with no major complications. Despite the cohort's high acuity and instability, outcomes were encouraging and comparable to those reported by ELSO for respective indications.

Despite substantial growth, ECLS remains limited to tertiary care centers and not readily available in the community due to the lack of infrastructure and resources at most hospitals. ${ }^{17,18}$ Although interhospital transfer may theoretically extend access to ECLS, many patients are unstable for conventional transport. Given the high population density and abundance of hospitals within our metropolitan region, we developed a ground-transportation-based retrieval program emphasizing referrals from our community rather than long distance transits. Our transport paradigm has several unique features. Most patients were cannulated in the ICU, avoiding difficult transport to the operating room. Except for patients who were already in the catheterization laboratory or operating room, our methodology does not require fluoroscopy or transesophageal echocardiography, facilitating our ability to rapidly initiate ECLS. This is particularly relevant because many outlying hospitals lack such resources, and provided the greatest flexibility for ECLS initiation. Using an experienced team and femoral cannulation, we initiated ECLS successfully in all candidates in a median time $<1$ hour from arrival. Although time to cannulation was not explicitly reported, Bryner and colleagues ${ }^{11}$ spent a mean of 7 hours at the referring facility before departure. Our initial efforts focused on ECLS transports within our community partly due to local need, avoiding the burden of an air-transportation-based program. An important consideration was the development of a dedicated on-call transport team for ECLS retrieval because contracting of independent ambulance and perfusion services may delay transports. Over time, we initiated a multidisciplinary conference call to review candidacy and logistics before each transport, which aided expediency and organization. Our results highlight the importance of planning and developing local ECLS networks for retrieval, even within large metropolitan areas that would hypothetically be well equipped to provide advanced therapies to all patients. These networks may have different working protocols depending upon the clinical needs of the area, health systems involved, and geographic considerations, 
TABLE 4. Comparison of demographic characteristics, clinical characteristics, and support duration for patients with COVID-19-respiratory failure versus non-COVID-19 respiratory failure

\begin{tabular}{|c|c|c|c|}
\hline Variable & Non-COVID-19 $(\mathrm{n}=52)$ & $\operatorname{COVID-19}(n=21)$ & $P$ value \\
\hline \multicolumn{4}{|l|}{ Demographics and clinical characteristics } \\
\hline Age (y) & $44.4(13.6)$ & $42.1(10.4)$ & .489 \\
\hline Female & $14(26.9)$ & $4(19.0)$ & .480 \\
\hline Race & & & .005 \\
\hline White & $25(48.1)$ & $1(4.8)$ & \\
\hline Black & $3(5.8)$ & $1(4.8)$ & \\
\hline Hispanic & $23(44.2)$ & $18(85.7)$ & \\
\hline Asian & $1(1.9)$ & $1(4.8)$ & \\
\hline BMI $\left(\mathrm{kg} / \mathrm{m}^{2}\right)$ & $32.6 \pm 8.0$ & $30.0 \pm 6.2$ & .181 \\
\hline Organ dysfunction other than pulmonary* & $28(53.9)$ & $5(23.8)$ & .020 \\
\hline \multicolumn{4}{|l|}{ Respiratory support before ECLS } \\
\hline Time from intubation to cannulation (h) & $48(16-96)$ & $30(20-72)$ & .316 \\
\hline Respiratory rate (breaths/min) & $20(16-30)$ & $30(25-32)$ & .002 \\
\hline PIP $\left(\mathrm{cm} \mathrm{H}_{2} \mathrm{O}\right)$ & $25(20-32)$ & $37(32-42)$ & .002 \\
\hline $\operatorname{PEEP}\left(\mathrm{cm} \mathrm{H}_{2} \mathrm{O}\right)$ & $14(10-18)$ & $14(10-15)$ & .560 \\
\hline Prone positioning & $14(26.9)$ & $19(90.5)$ & $<.001$ \\
\hline Hand-bagging & $2(4.4)$ & $2(12.5)$ & .264 \\
\hline \multicolumn{4}{|l|}{ Organ support or therapies before ECLS } \\
\hline Vasoactive Inotrope Score & $0(0-10)$ & $4(0-12)$ & .808 \\
\hline RESP risk class & & & .270 \\
\hline 1 & $12(23.1)$ & $1(4.8)$ & \\
\hline 2 & $12(23.1)$ & $7(33.3)$ & \\
\hline 3 & $16(30.8)$ & $10(47.6)$ & \\
\hline 4 & $8(15.4)$ & $2(9.5)$ & \\
\hline 5 & $4(7.7)$ & $1(4.8)$ & \\
\hline Dialysis & $8(15.4)$ & $1(4.8)$ & .211 \\
\hline Intravenous bicarbonate & $14(26.9)$ & $18(85.7)$ & $<.001$ \\
\hline Paralytics & $49(94.2)$ & $21(100.0)$ & .261 \\
\hline Epoprostenol or nitric oxide & $4(7.7)$ & $7(33.3)$ & .006 \\
\hline \multicolumn{4}{|l|}{ Pre-ECLS laboratory values } \\
\hline $\mathrm{PaO}_{2}: \mathrm{FIO}_{2}(\mathrm{~mm} \mathrm{Hg})$ & $65.2(55.0-79.5)$ & $59.0(52.2-64.0)$ & .016 \\
\hline $\mathrm{pH}$ & $7.28(7.19-7.37)$ & $7.24(7.09-7.33)$ & .211 \\
\hline $\mathrm{PaCO}_{2}(\mathrm{~mm} \mathrm{Hg})$ & $59.8(49.6-71.5)$ & $69.1(44.0-96.1)$ & .181 \\
\hline $\mathrm{PaO}_{2}(\mathrm{~mm} \mathrm{Hg})$ & $65.0(54.3-76.1)$ & $59.0(52.2-64.0)$ & .036 \\
\hline Bicarbonate $(\mathrm{mmol} / \mathrm{L})$ & $25.4(22.1-31.6)$ & $27.6(22.4-31.1)$ & .740 \\
\hline Base excess $(\mathrm{mmol} / \mathrm{L})$ & $0(-3.0$ to 5.2$)$ & 0.5 ( -3.9 to 3.9$)$ & .773 \\
\hline \multicolumn{4}{|l|}{ Duration of support and survival } \\
\hline Time on ECLS (h) & $188(106-364)$ & $625(403-898)$ & $<.001$ \\
\hline ICU LOS (d) & $14(8-21)$ & $32(24-37)$ & $<.001$ \\
\hline Total LOS (d) & $15(9-25)$ & $36(25-48)$ & $<.001$ \\
\hline Survival to decannulation & $42(80.8)$ & $12(57.1)$ & .037 \\
\hline Survival to discharge & $35(67.3)$ & $11(52.4)$ & .232 \\
\hline
\end{tabular}

Values are presented $\mathrm{n}(\%)$, median (interquartile range), or mean \pm SD. BMI, Body mass index; $E C L S$, extracorporeal life support; $P I P$, peak inspiratory pressure; $P E E P$, positive end expiratory pressure; RESP, Respiratory Extracorporeal Membrane Oxygenation Survival Prediction; ICU, intensive care unit; $L O S$, length of stay. *Organ dysfunction other than pulmonary included central nervous system, cardiac, renal, and hepatic.

but should focus on safety and efficiency during transportation. ${ }^{17}$

Interhospital transfer of patients on ECLS has been more commonly utilized for respiratory failure rather than cardiac indications. Several studies have reported reasonable survival rates for those cannulated by a mobile team and transferred to an ECLS center, ranging from $44 \%$ to
$67.5 \%{ }^{9-12}$ Compared with respiratory failure, metabolic and hemodynamic derangements that result in a need for VA-ECLS further limit capabilities to safely transport patients. In our community, an unmet need for management of such patients was identified: The county has $>40$ centers that perform cardiac surgery or urgent percutaneous coronary intervention with only 4 ELSO-certified adult ECLS 
An Efficient, Mobile ECLS Program for Cardiac and Respiratory Failure

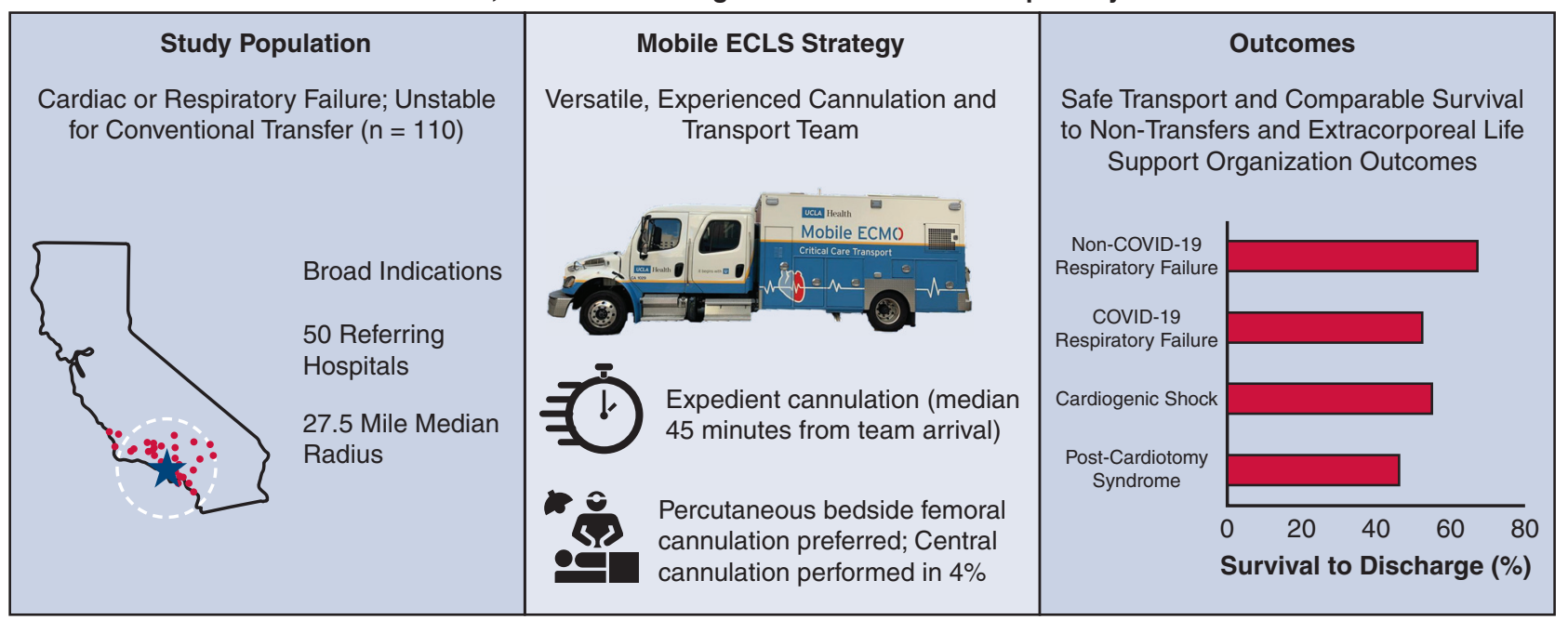

Mobile ECLS can be safely used to transfer unstable patients with promising outcomes!

ECLS, extracorporeal life support.

FIGURE 3. Overview of study population, mobile extracorporeal life support (ECLS) strategy, and outcomes of 110 patients transported on ECLS.

programs. ${ }^{1}$ In our cohort, approximately $30 \%$ of patients were placed on VA support, including 4 that were centrally cannulated, an ability greatly facilitated by deployment of a surgical team. The present study is among few examining retrieval for postcardiotomy syndrome directly from the referring hospital's operating room in cases where the patient cannot be separated from bypass. Moreover, in highly selected cases of cardiac arrest with intermittent return of spontaneous circulation, we successfully deployed a mobile retrieval team for initiation of ECLS, with acceptable survival. In March 2020, we expanded our program to include cannulation and transportation of patients with respiratory failure secondary to COVID-19. Compared with nonCOVID-19 respiratory failure, these patients had substantially more severe pulmonary disease, evidenced by higher inspiratory pressures, duration of ECLS support, and nearly all were refractory to conventional measures for acute respiratory distress syndrome, including prone positioning and paralysis.
Several studies have demonstrated interhospital transfer to be associated with increased risk of mortality or complications. $^{8,19-21}$ In the present work, survival rates for transported patients were comparable to all-comers as reported by ELSO as well as to those cannulated at our institution. This may be related to team expertise in selection, cannulation, and management. Prior institutional series have reported a significant proportion of cannulations being performed by the referring hospital or upon arrival at the receiving facility. ${ }^{9}$ In our experience, nearly all patients were cannulated by the mobile team due to limited expertise at outside hospitals. Immediate placement of a distal perfusion catheter in cases of peripheral VA-ECLS may be responsible for low rates of ipsilateral limb ischemia in our patients. All cases of limb ischemia were in the contralateral limb, or when cannulated by the referring physician without placement of distal perfusor. These results are encouraging and suggest the safety of a retrieval program, which allows for extension of ECLS to a local community

TABLE 5. Survival to discharge for patients transported on extracorporeal life support (ELCS), institutional nontransports, and outcomes reported by the Extracorporeal Life Support Organization (ELSO)

\begin{tabular}{lccc}
\hline \multicolumn{1}{c}{ Outcome } & Transports & Nontransports & ELSO survival to discharge/transfer \\
\hline Acute respiratory failure & $34(66.7)$ & $29(74.4)$ & $15,471(60.4)$ \\
Cardiogenic shock & $11(55.0)$ & $53(66.3)$ & $11,891(44.0)$ \\
Postcardiotomy syndrome & $6(46.2)$ & $13(54.2)$ & $8558(29.8)$ \\
ECPR & $3(75.0)$ & $32(47.1)$ & $1387(48.4)$ \\
COVID-19 & $11(52.4)$ & $5(62.5)$ & \\
\hline
\end{tabular}

Values are presented as n $(\%)$. For each indication, no statistically significant difference between transports and nontransports placed on ECLS from 2018 to 2021 ( $P>.05)$. No statistically significant difference between institutional transports and data reported by ELSO $(P>.05)$. Data reported from ELSO stratified into cardiac, respiratory, ECPR, and COVID-19 indications as defined in the ELSO Registry. ${ }^{1}$ Chronic respiratory failure not reported as $\mathrm{n}=1$ in transport cohort. ECPR, Extracorporeal cardiopulmonary resuscitation. 


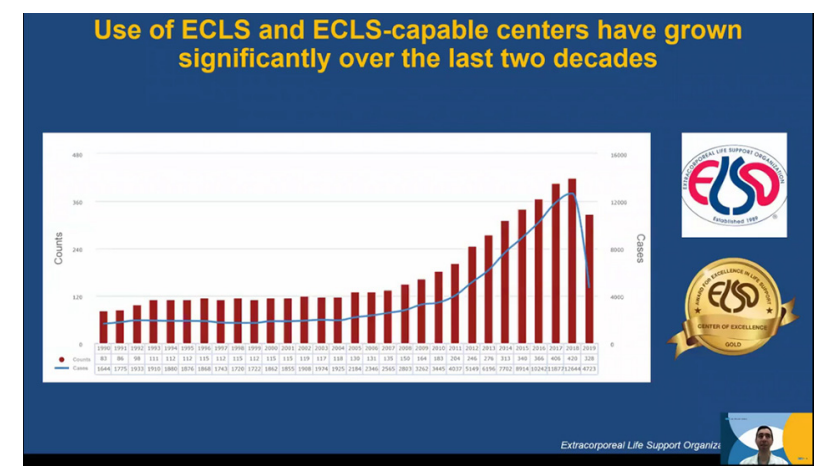

VIDEO 1. Authors briefly discuss the implementation and outcomes of mobile extracorporeal life support. Video available at: https://www.jtcvs. org/article/S2666-2507(22)00024-4/fulltext.

where resources may be lacking. Moreover, transfer to a tertiary care center provides access to multidisciplinary management, a dedicated cardiothoracic surgical ICU with expertise in ECLS, and evaluation for durable mechanical circulatory support or transplantation. Undoubtedly, a multidisciplinary approach for all phases of ECLS retrieval is needed to appropriately deliver this resource-intensive therapy to a group of patients who present to facilities without ECLS expertise.

The present study has several limitations, including its single-center design. Patients were selected for ECLS based on predicted risk of survival and perceived benefit of ECLS, potentially introducing selection bias. Patients selected for mobile cannulation and transfer were, by definition, unstable for conventional transfer and may have had more advanced presentation than non-transfers. At our institution, conventional transfer is utilized when patients are deemed stable, and candidacy and appropriateness for ECLS are reconsidered upon arrival. We are also limited by the lack of outcomes and risk profiles of those not selected for mobile ECLS. The present study is limited by the lack of data regarding the costs of the ECLS program and charges submitted to payers. Such financial considerations will vary by institution dependent on payer mix, fiscal cost of deploying a team, and transportation method. Time on ECLS, ICU length of stay, and hospital LOS may serve as surrogates of resource use and reflect the intensity of care. Ground-transportation-based retrieval is suited for metropolitan areas with many referring hospitals, whereas air transportation is likely necessary in rural regions. In areas where ECLS centers are further geographically, a model whereby several hub hospitals bridge travel distance and consolidate resources, may facilitate transfer. Our cohort experienced minimal delay to ECLS initiation, with shorter duration of mechanical ventilation before cannulation and significantly lower transport times compared with other institutional series, which may be difficult to achieve at less resourced centers. Finally, our mobile
ECLS team was not exclusively hired for transports and team members were utilized for non-ECLS duties, which may not be generalizable to other hospital systems.

\section{CONCLUSIONS}

We report the infrastructure and paradigm for our mobile ECLS program, and associated growth and outcomes (Video 1). Cannulation by a mobile team and subsequent transfer on ECLS to an experienced center appears safe and yields acceptable outcomes across broad indications, including postcardiotomy syndrome and COVID-19associated respiratory failure. Our simplified approach to cannulation and ground-transportation-based transit allows expeditious initiation of ECLS and extension of this service to local communities.

\section{Conflict of Interest Statement}

Dr Shemin is a consultant to the Edwards Lifesciences Advisory Board and a co-principal investigator of the Placement of Aortic Transcatheter Valves (PARTNER) II trial. All other authors reported no conflict of interest.

The Journal policy requires editors and reviewers to disclose conflicts of interest and to decline handling or reviewing manuscripts for which they may have a conflict of interest. The editors and reviewers of this article have no conflicts of interest.

The authors appreciate the invaluable role of the transport, nursing, respiratory therapy, physical and occupational therapy, social work, and case management staff in the care of the patients in this study.

University of California at Los Angeles Extracorporeal Life Support Group Members include Ida Anderson, MSN, RN; Stephanie Bland, CCP; David Boldt, MD, MS; Rene Cardiel, CCP; Wei Ting Chen, RN, CCRN; Jennie Chinchilla, Sara Crager, MD; Kim De La Cruz, CCP; Ryan Dries, CCP; Jessica Fries, CCP; Joseph Meltzer, MD; Jacquelyn Gates, MSN, RN, CCRN; Christopher Hernandez, EMT; Marisa Hernandez-Morgan, MD, MPP; Wolf B. Kratzert, MD, PhD; Nikoloz Kutateladze, CCP; Saba Lahar, CCP; George Lim, MD; Ann McNeil, MSN, RN, NE-BC; Katelyn Mears, CCP; Ashley Melendez, CCP; Curtis Murata; Christopher Ortiz, MD, PhD; Anthony Pagel, CCP; Prachi Redkar, CCP; Daniel Salib, CCP; Jessica Samson, CCP; Nancy Satou, RN; Lisa Toft, CCP; Savonna Warren, CCP; Michael Wolfe, MD; and Andrew Young, MD.

\footnotetext{
References

1. Extracorporeal life support organization - international summary. Accessed March 1, 2021. https://www.elso.org/Registry/Statistics.aspx

2. Sanaiha Y, Bailey K, Downey P, Seo YJ, Aguayo E, Dobaria V, et al. Trends in mortality and resource utilization for extracorporeal membrane oxygenation in the United States: 2008-2014. Surgery. 2019;165:381-8.

3. McCarthy FH, McDermott KM, Kini V, Gutsche JT, Wald JW, Xie D, et al. Trends in U.S. extracorporeal membrane oxygenation use and outcomes: 20022012. Semin Thorac Cardiovasc Surg. 2015;27:81-8.
} 
4. Hadaya J, Dobaria V, Aguayo E, Kwon OJ, Sanaiha Y, Hyunh A, et al. National trends in utilization and outcomes of extracorporeal support for in- and out-ofhospital cardiac arrest. Resuscitation. 2020;151:181-8.

5. Guglin M, Zucker MJ, Bazan VM, Bozkurt B, El Banayosy A, Estep JD, et al. Venoarterial ECMO for adults: JACC scientific expert panel. J Am Coll Cardiol. 2019;73:698-716.

6. Yoshioka D, Li B, Takayama H, Garan RA, Topkara VK, Han J, et al. Outcome of heart transplantation after bridge-to-transplant strategy using various mechanical circulatory support devices. Interact Cardiovasc Thorac Surg. 2017;25:918-24.

7. Todd EM, Biswas Roy S, Hashimi AS, Serrone R, Panchanathan R, Kang P, et al. Extracorporeal membrane oxygenation as a bridge to lung transplantation: a single-center experience in the present era. J Thorac Cardiovasc Surg. 2017; 154:1798-809.

8. Aguayo E, Kwon OJ, Dobaria V, Sanaiha Y, Hadaya J, Sareh S, et al. Impact of interhospital transfer on clinical outcomes and costs of extracorporeal life support. Surgery. 2020;168:193-7.

9. Ranney DN, Bonadonna D, Yerokun BA, Mulvihill MS, Al-Rawas N, Weykamp M, et al. Extracorporeal membrane oxygenation and interfacility transfer: a regional referral experience. Ann Thorac Surg. 2017;104:1471-8.

10. Biscotti M, Agerstrand C, Abrams D, Ginsburg M, Sonett J, Mongero L, et al. One hundred transports on extracorporeal support to an extracorporeal membrane oxygenation center. Ann Thorac Surg. 2015;100:34-40.

11. Bryner B, Cooley E, Copenhaver W, Brierley K, Teman N, Landis D, et al. Two decades' experience with interfacility transport on extracorporeal membrane oxygenation. Ann Thorac Surg. 2014;98:1363-70.

12. Wagner K, Sangolt GK, Risnes I, Karlsen HM, Nilsen JE, Strand T, et al. Transportation of critically ill patients on extracorporeal membrane oxygenation. Perfusion. 2008;23:101-6.

13. Koponen T, Karttunen J, Musialowicz T, Pietiläinen L, Uusaro A, Lahtinen P. Vasoactive-inotropic score and the prediction of morbidity and mortality after cardiac surgery. Br J Anaesth. 2019;122:428-36.

14. Na SJ, Chung CR, Cho YH, Jeon K, Suh GY, Ahn JH, et al. Vasoactive inotropic score as a predictor of mortality in adult patients with cardiogenic shock: medical therapy versus ECMO. Rev Esp Cardiol. 2019;72:40-7.
15. Schmidt M, Burrell A, Roberts L, Bailey M, Sheldrake J, Rycus PT, et al. Predicting survival after ECMO for refractory cardiogenic shock: the survival after veno-arterial-ECMO (SAVE)-score. Eur Heart J. 2015;36:2246-56.

16. Schmidt M, Bailey M, Sheldrake J, Hodgson C, Aubron C, Rycus PT, et al. Predicting survival after extracorporeal membrane oxygenation for severe acute respiratory failure: the Respiratory Extracorporeal Membrane Oxygenation Survival Prediction (RESP) score. Am J Respir Crit Care Med. 2014;189: 1374-82.

17. Zakhary B, Shekar K, Diaz R, Badulak J, Johnston L, Roeleveld PP, et al Position paper on global extracorporeal membrane oxygenation education and educational agenda for the future: a statement from the extracorporea life support organization ECMOed taskforce. Crit Care Med. 2020;48 406-14.

18. Ramanathan K, Antognini D, Combes A, Paden M, Zakhary B, Ogino M, et al Planning and provision of ECMO services for severe ARDS during the COVID19 pandemic and other outbreaks of emerging infectious diseases. Lancet Respir Med. 2020;8:518-26.

19. Allen L, Vogt K, Joos E, van Heest R, Saleh F, Widder S, et al. Impact of interhospital transfer on patient outcomes in emergency general surgery. Surgery. 2021;169:455-9.

20. Froehler MT, Saver JL, Zaidat OO, Jahan R, Aziz-Sultan MA, Klucznik RP, et al Interhospital transfer before thrombectomy is associated with delayed treatment and worse outcome in the STRATIS registry (systematic evaluation of patient treated with neurothrombectomy devices for acute ischemic stroke). Circulation. 2017; 136:2311-21.

21. Nallamothu BK, Bates ER, Herrin J, Wang Y, Bradley EH, Krumholz HM. Times to treatment in transfer patients undergoing primary percutaneous coronary intervention in the United States: National Registry of Myocardial Infarction (NRMI)-3/4 analysis. Circulation. 2005;111:761-7.

Key Words: extracorporeal membrane oxygenation, extracorporeal life support, transport, respiratory failure, cardiogenic shock, critical care, COVID-19 


\section{APPENDIX E1. MOBILE EXTRACORPOREAL LIFE SUPPORT (ECLS) PROGRAM LOGISTICS AND ORGANIZATION \\ Circuit Configuration and Cannulation Equipment}

The most commonly used cannulae for bifemoral venovenous ECLS were Medtronic (Minneapolis, Minn) Biomedicus multistage venous cannulae for drainage and single-stage cannulae for return. For venoarterial ECLS, Edwards Lifesciences (Irvine, Calif) Optisite cannulas are most commonly used. For each transport, we stocked at least 2 of each cannula, ranging from $19 \mathrm{Fr}$ to $25 \mathrm{Fr}$ for multistage venous, $19 \mathrm{Fr}$ to $23 \mathrm{Fr}$ for single stage venous, $17 \mathrm{Fr}$ to $21 \mathrm{Fr}$ for short single stage venous, and $16 \mathrm{Fr}$ to $20 \mathrm{Fr}$ for arterial cannulae.

Our primary circuit, used in approximately $97 \%$ of transports, included a Medtronic Bio-Console 560, Medtronic Affinity CP centrifugal blood pump, and Maquet (Getinge Group) Quadrox oxygenator with an oxygen flow meter on the gas tank. A heater cooler and blender are not brought to the transferring hospital, but added to the circuit upon arrival to our institution. We selected these components due to cost, availability, team familiarity, and reliability in our experience. A second, unprimed circuit is brought on transports, as well as an extra oxygenator, pump head, and hand crank.

\section{Cannulation, Transportation, and Patient Care}

We most commonly performed femoral percutaneous cannulation for ECLS because this can be readily performed at the bedside without imaging. For femoralfemoral venovenous ECLS, cannulas are positioned based on the patient's height and vessel depth, assessed by ultrasound. We have found that drainage and return cannulas are optimally positioned to reduce recirculation when separated by approximately $12 \mathrm{~cm}$. If evidence of recirculation is present, the drainage cannula is repositioned. We have found that a small degree of recirculation during transportation is not detrimental because cannulas can be repositioned upon arrival to our institution. For venoarterial ECLS, ECLS cannulas are placed and flow is initiated before placement of a distal perfusion cannula. ECLS flow is evaluated immediately after cannulation and administration of crystalloid or colloid is performed as needed. In cases of poor venous drainage, a short drainage cannula is placed in the right internal jugular vein. To ensure safe transport, cannulas are extensively secured with 0 -silk sutures and an Ioban (3M, St Paul, Minn) dressing, and connectors reinforced with sterile cable ties. A similar approach is used for patients requiring central venoarterial-ECLS, with the chest temporarily closed using Ioban. Ventilator settings are adjusted after initiation of ECLS, and patient arterial blood gas performed, with further adjustment in ventilator settings, sweep, or flow rate as needed.
Following cannulation, patients are prepared for transportation. All medications are transferred to our institution's infusion pumps and the patient is placed on a transport ventilator. Once ECLS is initiated, inhaled nitric oxide or epoprostenol is discontinued during transportation. Percutaneous ventricular assist device or intra-aortic balloon pump, if present, are continued and are transferred to controllers brought from the home institution. Patients are transported using an extended cab ambulance dedicated for ECLS transports; before purchase of an ECLS-dedicated ambulance, a rotating fleet of ground ambulances provided by our institution were used.

Upon arrival to our institution, all patients are admitted to a cardiothoracic surgery intensive care unit and are comanaged by the cardiothoracic surgery and surgical critical care teams. Heparin is used for anticoagulation, with a bolus (3000-5000 U) administered following wire access, followed by infusion. Three tiers of activated partial thromboplastin time goals are maintained depending on patient factors, flow rates, and venoarterial versus venovenous support: 35 to 49 seconds, 50 to 75 seconds, and 75 to $90 \mathrm{sec}-$ onds. Once patients are stabilized at our facility, neurologic status is routinely assessed within 24 hours. Daily decisions regarding ECLS management and overall patient care are made in a collaborative fashion by the cardiothoracic surgery and surgical critical care teams. Pulmonary medicine physicians are consulted for patients with underlying pulmonary disease or atypical progression of acute respiratory distress syndrome. Advanced heart failure and transplantation teams are consulted for those with underlying cardiomyopathy or heart failure as well as those who may require evaluation for long term mechanical support or transplantation. We have found that early involvement of palliative care to be imperative in patients who fail to improve on ECLS.

\section{Team Logistics and Training}

All individuals involved in the transport program, including perfusionists, respiratory therapists, emergency medical technicians, and critical care transport nurses are employed by our institution. These individuals provide inpatient care or transports for non-ECLS purposes. ECLS retrievals were one component of routine duties, and this team provided coverage using a schedule and call system. A complement of 10 emergency medical technicians, 7 critical care nurses, 5 respiratory therapists, and 10 perfusionists were involved in the transport efforts and comprised this call pool. One attending cardiothoracic surgeon performed all but 1 cannulation in this series with assistance of a pool of 4 surgical assistants.

All participants are trained annually regarding the logistics of transporting ECLS patients, including a simulation session that was held at the inception of the program. Perfusionists are extensively trained in the care of in-house ECLS 
patients before participating in the transport program, and are accompanied on at least 1 transport by a senior perfusionist. Standardized protocols for vasoactive agents, ventilator settings, and ECLS flow were developed and are reviewed in writing and verbally at every transport.

\section{Emergency Privileges, Malpractice, and Billing}

The Joint Commission requires all hospitals to develop a process by which physicians can obtain temporary privileges, including those related to specific patient care needs. Privileges for ECLS meets these criteria because it is considered a specialized skillset. In advance of team deployment, we contact the accepting physician and request emergency privileges for ECLS cannulation. These are immediately communicated with the chief medical officer of each hospital as well as the medical staff office. The level of documentation required varies by hospital, with some requiring only a copy of medical license and proof of employment. In some cases, approval is granted but the referring institution requires a full application to be formally submitted following cannulation. After verification of employment and liability insurance, privileges are granted. This process is typically completed in $<1$ hour. Liability insurance is provided by our institution and provides malpractice coverage as long as the procedure is within the scope of practice of the provider.

As transportation for ECLS is provided by our institution and not a third party, it is included in the diagnosisrelated group payment for ECLS services and not billed separately. Currently, billing for procedures (ECLS cannula placement and ECLS initiation) is not routinely performed by the cannulating physician. The logistics of correctly billing for this physician service are being addressed by our institutional financial team and is dependent on state law, as the service is rendered in a different hospital. 


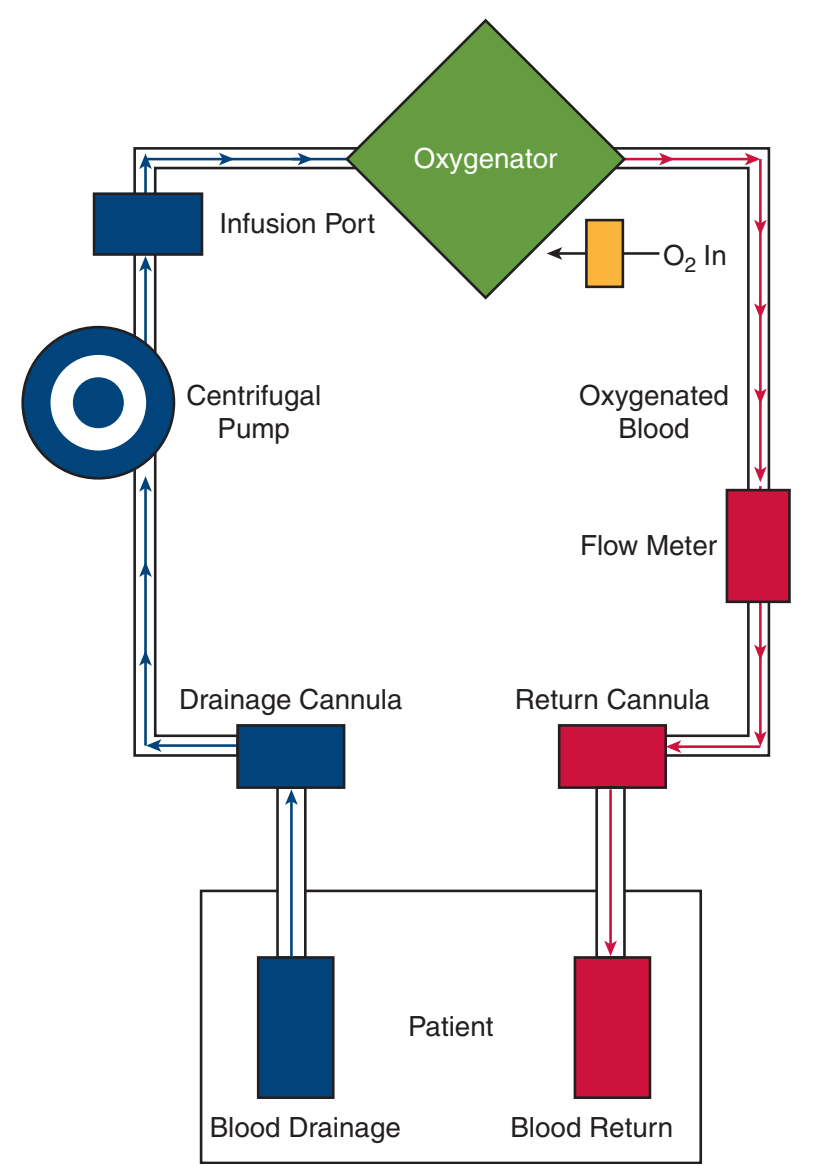

FIGURE E1. Diagram of mobile extracorporeal life support transport circuit. 
TABLE E1. Clinical characteristics of patients transported on extracorporeal life support (ECLS) stratified by indication for support

\begin{tabular}{|c|c|c|c|c|}
\hline Characteristic & $\begin{array}{c}\text { Non-COVID-19 respiratory } \\
\text { failure }(\mathbf{n}=\mathbf{5 2})\end{array}$ & $\begin{array}{c}\text { Cardiogenic } \\
\text { shock }(n=20)\end{array}$ & $\begin{array}{c}\text { Postcardiotomy } \\
\text { syndrome }(n=13)\end{array}$ & $\begin{array}{l}\text { COVID-19 respiratory } \\
\text { failure }(n=21)\end{array}$ \\
\hline Age (y) & $44.4(13.6)$ & $42.5(14.5)$ & $58.8(11.9)$ & $42.1(10.4)$ \\
\hline \multicolumn{5}{|l|}{ Sex } \\
\hline Male & $38(73.1)$ & $13(65.0)$ & $12(92.3)$ & $17(81.0)$ \\
\hline Female & $14(26.9)$ & $7(35.0)$ & $1(7.7)$ & $4(19.0)$ \\
\hline \multicolumn{5}{|l|}{ Race } \\
\hline White & $25(48.1)$ & $13(65.0)$ & $4(30.8)$ & $1(4.8)$ \\
\hline Hispanic & $23(44.2)$ & $3(15.0)$ & $2(15.4)$ & $18(85.7)$ \\
\hline Black & $3(5.8)$ & $1(5.0)$ & $3(23.1)$ & $1(4.8)$ \\
\hline Asian & $1(1.9)$ & $3(15.0)$ & $4(30.8)$ & $1(4.8)$ \\
\hline BMI $\left(\mathrm{kg} / \mathrm{m}^{2}\right)$ & $32.6(8.0)$ & $28.8(7.3)$ & $27.7(6.8)$ & $30.0(6.2)$ \\
\hline \multicolumn{5}{|l|}{ Vasoactive Inotrope Score } \\
\hline$\leq 5$ & $33(63.5)$ & $2(10.0)$ & $3(23.1)$ & $13(61.9)$ \\
\hline $6-20$ & $12(23.1)$ & $6(30.0)$ & $4(30.8)$ & $4(19.1)$ \\
\hline $20-50$ & $7(13.5)$ & $5(25.0)$ & $3(23.1)$ & $4(19.1)$ \\
\hline$>50$ & 0 & $7(35.0)$ & $3(23.1)$ & 0 \\
\hline \multicolumn{5}{|l|}{ SAVE or RESP risk class* } \\
\hline 1 & $12(23.1)$ & 0 & 0 & $1(4.8)$ \\
\hline 2 & $12(23.1)$ & $4(20.0)$ & 0 & $7(33.3)$ \\
\hline 3 & $16(30.8)$ & $7(35.0)$ & $4(30.8)$ & $10(47.6)$ \\
\hline 4 & $8(15.4)$ & $5(25.0)$ & $3(23.1)$ & $2(9.5)$ \\
\hline 5 & $4(7.7)$ & $4(20.0)$ & $6(46.2)$ & $1(4.8)$ \\
\hline \multicolumn{5}{|c|}{ Pre-ECLS laboratory findings } \\
\hline $\mathrm{PaO}_{2}: \mathrm{FIO}_{2}(\mathrm{~mm} \mathrm{Hg})$ & $65.2(55.0-79.5)$ & $65(47.6-122.3)$ & $244(66.0-344.4)$ & $59.0(52.2-64.0)$ \\
\hline $\mathrm{pH}$ & $7.28(7.19-7.37)$ & $7.24(7.10-7.33)$ & $7.26(7.25-7.37)$ & $7.24(7.09-7.33)$ \\
\hline $\mathrm{PaCO}_{2}(\mathrm{~mm} \mathrm{Hg})$ & $59.8(49.6-71.5)$ & $44(37.7-55.0)$ & $41.7(38.0-45.9)$ & $69.1(44.0-96.1)$ \\
\hline $\mathrm{PaO}_{2}(\mathrm{~mm} \mathrm{Hg})$ & $65.0(54.3-76.1)$ & $62.5(47.6-118.0)$ & $136.0(66.0-288.4)$ & $59.0(52.2-64.0)$ \\
\hline Bicarbonate $(\mathrm{mmol} / \mathrm{L})$ & $25.4(22.1-31.6)$ & $18.3(15.9-21.8)$ & $20.2(17.5-22.2)$ & $27.6(22.4-31.1)$ \\
\hline Base excess $(\mathrm{mmol} / \mathrm{L})$ & $0(-3.0$ to -5.2$)$ & $-7.8(-10.8$ to -5.2$)$ & $-5.8(-9.0$ to -3.5$)$ & $0.5(-3.9$ to -3.9$)$ \\
\hline \multicolumn{5}{|l|}{ Outcomes } \\
\hline Time on ECLS (h) & $188(106-364)$ & $153(69-254)$ & 136 (94-207) & $625(403-898)$ \\
\hline ICU LOS (d) & $14(8-21)$ & $10(6-20)$ & $13(9-19)$ & $32(24-37)$ \\
\hline Total LOS (d) & $15(9-25)$ & $12(7-28)$ & $15(9-23)$ & $36(25-48)$ \\
\hline Decannulated & $42(80.8)$ & $11(55.0)$ & $7(53.8)$ & $12(57.1)$ \\
\hline Survived to discharge & $35(67.3)$ & $11(55.0)$ & $6(46.2)$ & $11(52.4)$ \\
\hline
\end{tabular}

Values are presented as $\mathrm{n}(\%)$, mean $\pm \mathrm{SD}$, or median (interquartile range). BMI, Body mass index; SAVE, Survival After Veno-Arterial Extracorporeal Membrane Oxygenation; $R E S P$, Respiratory Extracorporeal Membrane Oxygenation Survival Prediction; $I C U$, intensive care unit; $L O S$, length of stay. *SAVE Risk Class reported for venoarterial ECLS group and RESP Risk Class reported for venovenous ECLS group. 
TABLE E2. Clinical characteristics of patients transported on extracorporeal life support (ECLS) compared with institutional nontransports

\begin{tabular}{|c|c|c|}
\hline Characteristic & All mobile ECLS $(n=110)$ & Nontransports $(n=299)$ \\
\hline Age (y) & $44.7(14.1)$ & $56.0(16.3)$ \\
\hline \multicolumn{3}{|l|}{ Sex } \\
\hline Male & $82(74.6)$ & $187(62.5)$ \\
\hline Female & $28(25.4)$ & $112(37.5)$ \\
\hline \multicolumn{3}{|l|}{ Race } \\
\hline White & $46(41.8)$ & $155(51.8)$ \\
\hline Hispanic & $47(42.7)$ & $79(26.4)$ \\
\hline Black & $8(7.3)$ & $28(9.4)$ \\
\hline Asian & $9(8.2)$ & $26(8.7)$ \\
\hline Other & 0 & $11(3.7)$ \\
\hline BMI $\left(\mathrm{kg} / \mathrm{m}^{2}\right)$ & $30.8(7.6)$ & $27.6(6.8)$ \\
\hline \multicolumn{3}{|l|}{ ECLS configuration } \\
\hline Venovenous, peripheral & $72(66.4)$ & $64(21.4)$ \\
\hline Venoarterial, central & $4(3.6)$ & $38(12.7)$ \\
\hline Venoarterial, peripheral & $33(30.0)$ & $197(65.9)$ \\
\hline \multicolumn{3}{|l|}{ Indication } \\
\hline Acute respiratory failure & $51(46.4)$ & $39(13.0)$ \\
\hline COVID-19 & $21(19.1)$ & $8(2.7)$ \\
\hline Chronic respiratory failure & $1(0.9)$ & $33(11.0)$ \\
\hline Cardiogenic shock & $20(18.2)$ & $80(26.8)$ \\
\hline Postcardiotomy syndrome & $13(11.8)$ & $24(8.0)$ \\
\hline ECPR & $4(3.6)$ & $68(22.7)$ \\
\hline $\begin{array}{l}\text { Posttransplant graft } \\
\text { dysfunction }\end{array}$ & 0 & $18(6.0)$ \\
\hline Periprocedural support & 0 & $29(9.7)$ \\
\hline \multicolumn{3}{|l|}{$\begin{array}{l}\text { Organ dysfunction before } \\
\text { ECLS }\end{array}$} \\
\hline CNS dysfunction & $10(9.1)$ & $28(9.4)$ \\
\hline Prior cardiac arrest & $20(18.2)$ & $116(38.8)$ \\
\hline Liver dysfunction & $9(8.2)$ & $48(16.1)$ \\
\hline Acute kidney injury & $51(46.4)$ & $113(37.8)$ \\
\hline Time on ECLS (h) & $188(97-459)$ & $98(45-171)$ \\
\hline
\end{tabular}

